\title{
Risk evaluation of new-onset atrial fibrillation complicating ST-segment elevation myocardial infarction: a comparison between GRACE and $\mathrm{CHA}_{2} \mathrm{DS}_{2}$-VASc scores
}

This article was published in the following Dove Press journal:

Clinical Interventions in Aging

\section{Jiachen Luo' \\ Liming Dai' \\ Jianming $\mathrm{Li}^{2}$ \\ Jinlong Zhao' \\ Zhiqiang $\mathrm{Li}^{\prime}$ \\ Xiaoming Qin' \\ Hongqiang $\mathrm{Li}^{\prime}$ \\ Baoxin Liu' \\ Yidong Wei ${ }^{1}$}

'Department of Cardiology, Shanghai Tenth People's Hospital, Tongji University School of Medicine, Shanghai, People's Republic of China; ${ }^{2}$ Department of Cardiovascular Division, Minneapolis Veterans Affairs Medical Center, Minneapolis, MN, USA
Correspondence: Yidong Wei Department of Cardiology, Shanghai Tenth People's Hospital, Tongji University School of Medicine, 30I Middle Yanchang Road, Jingan District, Shanghai 200072,

People's Republic of China

Tel $+86186 \quad 17683409$

Fax $+862 \mid 6598$ I77|

Email tjyidong_wei@।63.com

\begin{abstract}
Purpose: New-onset atrial fibrillation (NOAF) is a common finding in patients with myocardial infarction (MI), but few studies are available regarding the prediction model for its risk estimation. Although Global Registry of Acute Coronary Events (GRACE) risk score (RS) has been recognized as an effective tool for the risk evaluation of clinical outcomes in patients with MI, its usefulness in the prediction of post-MI NOAF remains unclear. In this study, we sought to validate the discrimination performance of GRACE RS in the prediction of post-MI NOAF and to make a comparison with that of the $\mathrm{CHA}_{2} \mathrm{DS}_{2}$-VASc score in patients with ST-segment elevation myocardial infarction (STEMI).
\end{abstract}

Patients and methods: A total of 488 patients with STEMI who were admitted to our hospital between May 2015 and October 2016 without a history of atrial fibrillation were retrospectively evaluated in this study. GRACE and $\mathrm{CHA}_{2} \mathrm{DS}_{2}-\mathrm{VASc}$ scores were calculated for each patient. Patients were divided into low (GRACE RS $\leq 125$ )-, intermediate (GRACE RS 126-154)-, and high (GRACE RS $\geq 155$ )-risk groups. Receiver operating characteristic curve analyses were performed to evaluate the discrimination performance of both RSs. Model calibration was evaluated by using Hosmer-Lemeshow goodness-of-fit test (HLS).

Results: Of the 488 eligible patients, 49 (10.0\%) developed NOAF during hospitalization. In the overall cohort, the discrimination performance of GRACE RS (C-statistic: $0.76,95 \% \mathrm{CI}$ : $0.72-0.80$ ) was significantly better than that of $\mathrm{CHA}_{2} \mathrm{DS}_{2}$-VASc score (C-statistic: $0.68,95 \%$ CI: 0.64-0.72; comparison $p=0.03$ ). For subgroup analysis, GRACE RS tended to be better than the $\mathrm{CHA}_{2} \mathrm{DS}_{2}$-VASc score in all but the intermediate-risk group as evidenced by $\mathrm{C}$-statistics of 0.60 and 0.65 for GRACE and $\mathrm{CHA}_{2} \mathrm{DS}_{2}$-VASc scores, respectively. Excellent calibration was achieved except for GRACE RS in females (HLS $p=0.05$ ).

Conclusion: The diagnostic performance of GRACE RS is relatively high as well as better than that of the $\mathrm{CHA}_{2} \mathrm{DS}_{2}-\mathrm{VASc}$ score with respect to the prediction of post-MI NOAF.

Keywords: myocardial infarction, atrial fibrillation, GRACE risk score, $\mathrm{CHA}_{2} \mathrm{DS}_{2}-\mathrm{VASc}$ score, risk prediction

\section{Introduction}

New-onset atrial fibrillation (NOAF) is a common finding with a reported incidence ranging from $4 \%$ to $21 \%$ in patients who are diagnosed with myocardial infarction (MI) and free from previous atrial fibrillation (AF). The prognostic impact of post-MI NOAF has been extensively studied during the past decades. ${ }^{1-3}$ In a previous meta-analysis, Jabre et al showed that post-MI NOAF was significantly associated with mortality and 
suggested that NOAF should be perceived as an independent risk factor for clinical outcomes rather than simply a risk indicator reflecting the severity of $\mathrm{MI} .{ }^{4}$ Although the strategies for pre-existing AF management in patients with MI have been suggested in current clinical guidelines, ${ }^{5}$ it is still unclear whether a specific treatment (eg, anticoagulation therapy) should also be applied to those with NOAF. On the other hand, there is still no dedicated scoring system available for the risk estimation of NOAF in the setting of MI, which may limit the selection of patients with MI who are appropriate for clinical trials of anticoagulation therapy, heart failure management, or other novel therapies to improve outcomes after NOAF.

The $\mathrm{CHA}_{2} \mathrm{DS}_{2}-\mathrm{VASc}$ score has been recognized as an effective tool for the risk evaluation of ischemic stroke in patients with AF. ${ }^{6}$ In addition, the clinical utility of $\mathrm{CHA}_{2} \mathrm{DS}_{2}-\mathrm{VASc}$ score in predicting AF per se has been validated in a recently published study. ${ }^{7}$ In contrast, when applying $\mathrm{CHA}_{2} \mathrm{DS}_{2}$-VASc score in an ST-segment elevation myocardial infarction (STEMI) cohort for the prediction of subsequent NOAF, the discrimination was poor as evidenced by a C-statistic of $0.68,{ }^{8}$ thus indicating the need for further research to propose a scoring system that is more effective than the $\mathrm{CHA}_{2} \mathrm{DS}_{2}-\mathrm{VASc}$ score regarding the risk estimation of post-MI NOAF.

Global Registry of Acute Coronary Events (GRACE) risk score (RS) is originally proposed for the risk evaluation of mortality in patients with acute coronary syndrome (ACS). ${ }^{9}$ Furthermore, it has now been validated as an important tool for the risk stratification of prognosis in various clinical settings. ${ }^{10,11}$ Nevertheless, the diagnostic performance of GRACE RS in the risk assessment of post-MINOAF remains to be investigated. Given the fact that the individual components, such as age and heart failure, included in GRACE RS have been considered as the main risk factors for AF, ${ }^{12,13}$ we sought to validate the discrimination performance of GRACE RS for the prediction of post-MI NOAF, and to make a comparison with $\mathrm{CHA}_{2} \mathrm{DS}_{2}-\mathrm{VASc}$ score, using data from a STEMI cohort.

\section{Patients and methods}

\section{Study population}

The electronic medical records of all patients with STEMI who were admitted to the coronary care unit of Shanghai Tenth People's Hospital between May 2015 and October 2016 were reviewed. The diagnosis of STEMI was based on the criteria of the Third Universal Definition of Myocardial infarction. ${ }^{14}$ Patients were included if they were 18 years old or older and were admitted within 24 hours of the onset of ischemic chest pain; those who had pre-existing AF based on medical records, presented with AF at entry, underwent emergent bypass surgery or had missing data of the individual components of GRACE and $\mathrm{CHA}_{2} \mathrm{DS}_{2}-\mathrm{VASc}$ scores were excluded. The investigational review committee of Shanghai Tenth People's Hospital had approved the study protocol. Informed consent was not required by the Institutional Review Board for the observational nature of our study.

\section{Study design}

The GRACE 2.0 ACS Risk Calculator (see: http://www. outcomes-umassmedorg/grace/files/GRACE RiskModel Coefficients.pdf) was used in our study to calculate the GRACE RS in which eight prognostic factors were included: age, on-admission heart rate, systolic blood pressure (SBP) and Killip class or diuretic usage, baseline creatinine level or a history of chronic kidney dysfunction (CKD), ST-segment deviation, elevated troponin or other necrosis cardiac biomarkers, and on-admission cardiac arrest. ${ }^{15}$ Notably, based on our inclusion criteria, ST-segment deviation and elevated troponin were qualified as "true" for each patient.

Each factor included in $\mathrm{CHA}_{2} \mathrm{DS}_{2}$-VASc score (congestive heart failure [CHF], hypertension, age [65-74 years], diabetes, vascular disease, and sex category [female]) was assigned 1 point, except the age $\geq 75$ years and stroke/ transient ischemic attack, which were assigned 2 points, leading to a maximum score of 9 points.

\section{Definitions}

AF was defined as the absence of $\mathrm{P}$ waves with irregular $\mathrm{RR}$ intervals lasting for at least 30 seconds. NOAF was considered as patients with no history of AF who presented with sinus rhythm at entry and developed AF during the index hospitalization. Definitions of other baseline characteristics are presented in Table S1.

\section{Statistical analysis}

The baseline data were compared using an independentsample $t$-test for normally distributed continuous variables, Wilcoxon rank-sum test for skewed variables, and $\chi^{2}$ or Fisher's exact tests for categorical variables. Univariate logistic regression analysis was performed to identify which baseline characteristics were associated with post-MINOAF. After including each of these confounding factors as evidenced by a $p$-value $<0.05$ in the univariate analysis, multivariate logistic regression models were used to determine the independent risk factors for post-MI NOAF. Receiver 
operating characteristic curve analysis was performed to evaluate the discrimination performance of GRACE and $\mathrm{CHA}_{2} \mathrm{DS}_{2}$-VASc scores. We used the method described by Hanley and McNeil to compare the correlated C-statistic. ${ }^{16}$ Model calibration was evaluated according to the HosmerLemeshow goodness-of-fit test (HLS). All patients were divided into three groups based on GRACE risk categories (low-risk $\leq 125$, intermediate-risk 126-154, and highrisk $\geq 155$ ), the associations between NOAF incidence and GRACE and $\mathrm{CHA}_{2} \mathrm{DS}_{2}-\mathrm{VASc}$ scores stratification were assessed using Spearman rank correlation test, respectively. We also explored the sex-based differences in both RSs when evaluating the risk of NOAF. A two-sided $p<0.05$ was considered statistically significant for all analyses. All these tests were performed using SPSS Statistics version 22.0 (IBM Corporation, Armonk, NY, USA).

\section{Results}

A total of 527 patients with STEMI were identified between May 2015 and October 2016. After applying the exclusion criteria, the final study cohort comprised a total of 488 patients with STEMI who did not have a history of AF (Figure 1). Baseline demographic and clinical characteristics of the patients are summarized in Table 1. The overall incidence of post-MI NOAF was $10.0 \%(n=49)$. Of the study population, the mean age was 65 years and $101(21 \%)$ patients were women. Patients who suffered NOAF during hospitalization were older and more likely to be women compared with those not developing NOAF. A higher proportion of NOAF patients had a history of CKD and CHF as well as a higher level of initial Killip class in comparison with those not developing NOAF. GRACE and $\mathrm{CHA}_{2} \mathrm{DS}_{2}$-VASc scores were higher in NOAF patients compared with those in sinus rhythm. In addition, patients with

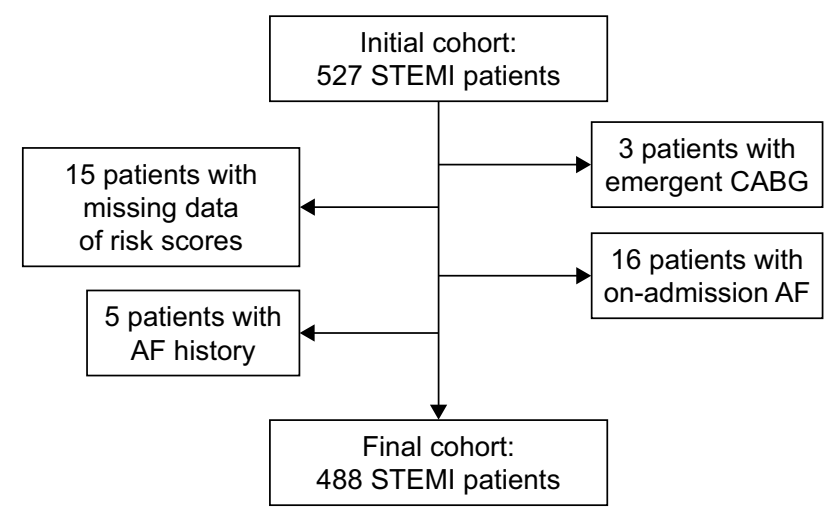

Figure I Flow diagram of patients identification.

Abbreviations: AF, atrial fibrillation; CABG, coronary artery bypass grafting; STEMI, ST-segment elevation myocardial infarction.
NOAF had a higher brain natriuretic peptide level, a larger atrial diameter and a lower ejection fraction compared with those not developing NOAF. A higher proportion of NOAF patients were receiving diuretic or inotrope treatment during hospitalization compared with no NOAF subjects (Table 2). Baseline characteristics of included patients categorized by sex and GRACE RS stratification are shown in Tables S2 and $\mathrm{S} 3$, respectively.

\section{Association between NOAF incidence and GRACE and $\mathrm{CHA}_{2} \mathrm{DS}_{2}$-VASc scores stratification}

Figure 2 illustrates the post-MI NOAF incidence increased in a graded manner across GRACE RS (range: $4.2 \%-22.9 \%$ ) and $\mathrm{CHA}_{2} \mathrm{DS}_{2}$-VASc score stratification (range: $1.9 \%-13.0 \%$ ). Furthermore, the association between NOAF incidence and GRACE RS stratification $(r=0.24, p<0.01)$ tended to be more robust than that between NOAF incidence and $\mathrm{CHA}_{2} \mathrm{DS}_{2}-$ VASc score stratification $(r=0.14, p<0.01)$.

\section{The discrimination performance of GRACE and $\mathrm{CHA}_{2} \mathrm{DS}_{2}$-VASc scores}

The GRACE RS showed a high discrimination performance for the prediction of post-MI NOAF as evidenced by a C-statistic of 0.76 (95\% CI: 0.72-0.80) in the overall population, which was better than that of the $\mathrm{CHA}_{2} \mathrm{DS}_{2}-\mathrm{VASc}$ score (C-statistic: $0.68,95 \%$ CI: $0.64-0.72$; comparison $p=0.03$; Figure $3 \mathrm{~A}$ ). In subgroup analyses, we illustrated the usefulness of GRACE RS in both men and women appeared to be better than that of the $\mathrm{CHA}_{2} \mathrm{DS}_{2}-\mathrm{VASc}$ score, although the superiority had not reached significance (Figure 3B and C). Of note, only a suboptimal calibration (HLS $p=0.05$ ) of GRACE RS was achieved in females. In addition, the diagnostic performance of GRACE RS tended to be better than that of the $\mathrm{CHA}_{2} \mathrm{DS}_{2}-\mathrm{VASc}$ score in all risk categories except for the intermediate-risk group, in which GRACE RS (C-statistic: 0.60, 95\% CI: 0.51-0.69) was inferior to $\mathrm{CHA}_{2} \mathrm{DS}_{2}-\mathrm{VASc}$ score (C-statistic: $0.65,95 \% \mathrm{CI}$ : 0.56-0.73). Both RSs achieved excellent calibration in all risk categories (Figure 3D-F). The sensitivity and specificity of GRACE and $\mathrm{CHA}_{2} \mathrm{DS}_{2}-\mathrm{VASc}$ scores for the prediction of post-MI NOAF are presented in Table S4.

\section{Independent risk factors for post-MI NOAF}

As shown in Table 3, advanced age was demonstrated as the only independent factor for post-MI NOAF in the overall 
Table I Baseline characteristics of included patients

\begin{tabular}{|c|c|c|c|c|}
\hline Characteristics & $\begin{array}{l}\text { Total } \\
(n=488)\end{array}$ & $\begin{array}{l}\text { Sinus rhythm } \\
(n=439)\end{array}$ & $\begin{array}{l}\text { NOAF } \\
(n=49)\end{array}$ & $p$-value \\
\hline Age (years) & $65.0 \pm 12.5$ & $64.0 \pm 12.3$ & $74.0 \pm 10.8$ & $<0.01$ \\
\hline Female (\%) & I0I (20.7) & $81(18.5)$ & $20(40.8)$ & $<0.01$ \\
\hline Hypertension (\%) & $313(64.1)$ & $280(63.8)$ & $33(67.3)$ & 0.62 \\
\hline Diabetes (\%) & $166(34.0)$ & $149(33.9)$ & $17(34.7)$ & 0.92 \\
\hline Dyslipidemia (\%) & $286(58.6)$ & $253(57.6)$ & $33(67.3)$ & 0.19 \\
\hline Smoker (\%) & $245(50.2)$ & $233(53.1)$ & $12(24.5)$ & $<0.01$ \\
\hline CKD (\%) & $108(22.1)$ & $90(20.5)$ & $18(36.7)$ & 0.01 \\
\hline $\mathrm{CHF}(\%)$ & $85(17.4)$ & $70(15.9)$ & $15(30.6)$ & 0.01 \\
\hline Previous stroke/TIA (\%) & $50(10.2)$ & $45(10.3)$ & $5(10.2)$ & 0.99 \\
\hline Previous vascular disease (\%) & $44(9.0)$ & $39(8.9)$ & $5(10.2)$ & 0.97 \\
\hline Previous MI (\%) & $23(4.7)$ & $21(4.8)$ & $2(4.1)$ & 1.00 \\
\hline Previous PCl (\%) & $36(7.4)$ & $31(7.1)$ & $5(10.2)$ & 0.61 \\
\hline \multicolumn{5}{|c|}{ Clinical presentations and outcomes } \\
\hline On-admission Killip class (\%) & & & & $<0.01$ \\
\hline I & $393(80.5)$ & $363(82.7)$ & $30(6 \mid .2)$ & \\
\hline II & $67(13.7)$ & $56(12.8)$ & II (22.4) & \\
\hline III-IV & $28(5.7)$ & $20(4.5)$ & $8(16.4)$ & \\
\hline On-admission HF (\%) & $95(19.5)$ & $76(17.3)$ & $19(38.8)$ & $<0.01$ \\
\hline On-admission SBP (mmHg) & $132(\mid 16-148)$ & $132(|| 8-\mid 48)$ & $127(108-\mid 46)$ & 0.16 \\
\hline On-admission HR (bpm) & $80(70-90)$ & $79(70-90)$ & $81(70-94)$ & 0.42 \\
\hline Cardiac arrest $(\%)$ & $\mathrm{II}(2.3)$ & $9(2.1)$ & $2(4.1)$ & 0.69 \\
\hline $\mathrm{CHA}_{2} \mathrm{DS}_{2}$-VASc score & $2(I-4)$ & $2(I-3)$ & $3(2-5)$ & $<0.01$ \\
\hline GRACE risk score & $120(102-140)$ & II7 (99-136) & $142(|29-| 7 \mid)$ & $<0.01$ \\
\hline In-hospital death (\%) & $26(5.3)$ & $19(4.3)$ & $7(14.3)$ & 0.01 \\
\hline Hospitalization (days) & $7(5-9)$ & $7(5-9)$ & $10(7-14)$ & $<0.01$ \\
\hline
\end{tabular}

Notes: aOn admission Killip class $>$ I. Data presented as $n$ (\%), mean \pm SD or median (IQR).

Abbreviations: CHF, congestive heart failure; CKD, chronic kidney dysfunction; GRACE, Global Registry of Acute Coronary Events; HF, heart failure; HR, heart rate; IQR, interquartile range; MI, myocardial infarction; NOAF, new-onset atrial fibrillation; PCI, percutaneous coronary intervention; SBP, systolic blood pressure; TIA, transient ischemic attack.

population (OR: $1.63,95 \%$ CI: $1.17-2.26 ; p<0.01$ ) based on the multivariable logistic regression model.

\section{Discussion}

\section{Main findings}

The main findings were as follows. First, the incidence of post-MI NOAF increased in a stepwise manner with the increase of GRACE and $\mathrm{CHA}_{2} \mathrm{DS}_{2}$-VASc score risk stratification. Second, the diagnostic performance of GRACE RS for the prediction of post-MI NOAF during hospitalization was relatively high as well as better than that of the $\mathrm{CHA}_{2} \mathrm{DS}_{2}$-VASc score. Notably, GRACE RS had a better discriminative value than the $\mathrm{CHA}_{2} \mathrm{DS}_{2}$-VASc score in all subgroups except in the intermediate-risk group. Third, caution should be noted when evaluating the risk of post-MI NOAF in females with the use of GRACE RS given its suboptimal calibration.

The detrimental impact of post-MI NOAF has been extensively studied. ${ }^{1,3,4}$ In line with previous studies, we also showed that NOAF complicating STEMI was associated with a nearly 3.7-fold increased risk of in-hospital death (OR: 3.72, 95\% CI: 1.48-9.36). NOAF may lead to adverse outcomes in patients with MI through several pathways, such as loss of atrioventricular synchrony and atrial constriction, and rapid heart rate, leading to the deterioration of heart failure; intra-cardiac thrombus formation contributing to ischemic stroke or systemic embolism. ${ }^{3,4,17}$ However, few studies with respect to the establishment of prediction models for the risk evaluation of post-MI NOAF have been conducted. ${ }^{8}$

While the $\mathrm{CHA}_{2} \mathrm{DS}_{2}-\mathrm{VASc}$ score is recommended for the risk evaluation of ischemic stroke in patients with $\mathrm{AF},{ }^{6}$ several previous studies ${ }^{7,8}$ had been performed to explore its clinical utility in the prediction of AF per se. In a population-based study, the usefulness of both $\mathrm{CHADS}_{2}$ and $\mathrm{CHA}_{2} \mathrm{DS}_{2}-\mathrm{VASc}$ scores in NOAF prediction was investigated in participants with no history of AF, the results of which (C-statistics: 0.73 and 0.74 for $\mathrm{CHADS}_{2}$ and $\mathrm{CHA}_{2} \mathrm{DS}_{2}$-VASc scores, respectively) seemed to advocate its utility. ${ }^{7}$ Of note, their results may not be extended to patients with MI. Indeed, in an ACS cohort, Mitchell and colleagues showed that both $\mathrm{CHADS}_{2}$ and $\mathrm{CHA}_{2} \mathrm{DS}_{2}$-VASc scores were ineffective for the prediction of incident AF. ${ }^{18}$ Similarly, in our study, the diagnostic performance of $\mathrm{CHA}_{2} \mathrm{DS}_{2}-\mathrm{VASc}$ score was relatively poor as evidenced by a C-statistic of 0.68 . 
Table 2 In-hospital examination and treatment

\begin{tabular}{|c|c|c|c|c|}
\hline Characteristics & Total $(n=488)$ & Sinus rhythm $(n=439)$ & NOAF $(n=49)$ & $p$-value \\
\hline \multicolumn{5}{|l|}{ Laboratory test } \\
\hline Hemoglobin (g/L) & $139(128-150)$ & $140(|28-| 5 \mid)$ & $134(|29-| 44)$ & 0.03 \\
\hline WBC $\left(\times 10^{\circ} / \mathrm{L}\right)$ & $9.68(7.82-12.06)$ & $9.50(7.77-12.09)$ & $9.72(6.94-12.26)$ & 0.70 \\
\hline Platelet $\left(\times 10^{9} / \mathrm{L}\right)$ & $204(169-243)$ & $203(|7|-246)$ & $183(157-238)$ & 0.14 \\
\hline C-reactive protein $(\mathrm{mg} / \mathrm{L})$ & $4.09(1.16-17.86)$ & $3.80(1.16-17.50)$ & $6.80(1.4|-| 8.42)$ & 0.62 \\
\hline Creatinine $(\mu \mathrm{mol} / \mathrm{L})$ & $80.8(67.9-96.3)$ & $80.0(67.8-95.9)$ & $81.0(67.2-107.8)$ & 0.40 \\
\hline eGFR $\left(\mathrm{mL} / \mathrm{min} / \mathrm{l} .73 \mathrm{~m}^{2}\right)$ & $83.0 \pm 26.2$ & $84.5 \pm 26.1$ & $70.1 \pm 23.5$ & $<0.01$ \\
\hline Peak TnT (ng/mL) & $5.35(1.79-10.00)$ & $5.11(1.80-10.00)$ & $8.25(1.29-10.00)$ & 0.25 \\
\hline$>100 \times U L N^{a}(n g / m L)$ & $390(79.9)$ & $354(80.6)$ & $36(73.5)$ & 0.24 \\
\hline Peak NT-pro-BNP (pg/mL) & I,762.5 (93।.7-3,908.0) & I,59I.0 (839.7-3,259.0) & $6,126.0(1,962.5-12,516.0)$ & $<0.01$ \\
\hline$>5 \times \mathrm{ULN}^{\mathrm{b}}(\mathrm{pg} / \mathrm{mL})$ & $312(63.9)$ & $267(60.8)$ & $45(91.8)$ & $<0.01$ \\
\hline \multicolumn{5}{|l|}{ Echocardiographyc } \\
\hline LVEF (\%) & $50.6 \pm 10.5$ & $51.1 \pm 10.2$ & $45.9 \pm 12.3$ & 0.01 \\
\hline Left atrial diameter $(\mathrm{mm})$ & $39.0 \pm 4.7$ & $38.9 \pm 4.6$ & $40.6 \pm 5.3$ & 0.02 \\
\hline LVESD $(\mathrm{mm})$ & $31.7 \pm 5.4$ & $31.5 \pm 5.2$ & $33.0 \pm 6.8$ & 0.36 \\
\hline LVEDD (mm) & $45.8 \pm 4.9$ & $45.9 \pm 4.8$ & $45.2 \pm 5.9$ & 0.16 \\
\hline Mitral regurgitation (\%) & & & & 0.35 \\
\hline Mild & $220(48.4)$ & $200(48.9)$ & $20(43.5)$ & \\
\hline Moderate & $24(5.3)$ & $20(4.9)$ & $4(8.7)$ & \\
\hline Severe & $2(0.4)$ & $I(0.2)$ & I (2.2) & \\
\hline Impaired mitral function (\%) & $26(5.7)$ & $21(5.1)$ & $5(10.9)$ & 0.21 \\
\hline \multicolumn{5}{|l|}{ Coronary angiography (\%) } \\
\hline Ischemia-related artery & & & & 0.97 \\
\hline LAD & $248(5 I .6)$ & $223(5 I .4)$ & $25(53.2)$ & \\
\hline RCA & $191(39.7)$ & $173(39.9)$ & $18(38.3)$ & \\
\hline LCX & $42(8.7)$ & $38(8.8)$ & $4(8.5)$ & \\
\hline Multi-vessel disease & $203(42.2)$ & $189(43.5)$ & $14(29.8)$ & 0.07 \\
\hline \multicolumn{5}{|l|}{ In-hospital treatment (\%) } \\
\hline Antiplatelets ${ }^{f}$ & $483(99.0)$ & $435(99.1)$ & $48(98.0)$ & $0.4 \mathrm{I}$ \\
\hline ACEI/ARB & $290(59.7)$ & $260(59.5)$ & $30(6 \mid .2)$ & 0.82 \\
\hline$\beta$-blockers & $356(73.3)$ & $321(73.5)$ & $35(71.4)$ & 0.76 \\
\hline $\mathrm{CCB}$ & $66(13.6)$ & $60(13.7)$ & $6(12.2)$ & 0.77 \\
\hline Statins & $476(97.9)$ & $430(98.4)$ & $46(93.9)$ & 0.11 \\
\hline Diuretic & $169(34.8)$ & $132(30.2)$ & $37(75.5)$ & $<0.01$ \\
\hline Inotropes & $159(32.7)$ & $132(30.2)$ & $27(55.1)$ & $<0.01$ \\
\hline $\mathrm{PCl}$ & $4 \mid 3(84.6)$ & $375(85.4)$ & $38(77.6)$ & 0.15 \\
\hline IABP & $25(5.3)$ & $19(4.3)$ & $7(14.3)$ & 0.01 \\
\hline Temporary pacemaker & $132(27.0)$ & $119(27.1)$ & $13(26.5)$ & 0.93 \\
\hline
\end{tabular}

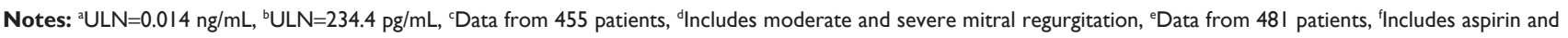
$\mathrm{P}_{2} \mathrm{Y}_{12}$ inhibitors. Data presented as $\mathrm{n}(\%)$, mean $\pm \mathrm{SD}$ or median (IQR).

Abbreviations: ACEI/ARB, angiotensin-converting enzyme inhibitor/angiotensin receptor blocker; CCB, calcium channel blocker; eGFR, estimated glomerular filtration rate; IABP, intra-aorta balloon pump; LAD, left anterior artery; LCX, left circumflex artery; LVEDD, left ventricular end-diastolic diameter; LVEF, left ventricular ejection fraction; LVESD, left ventricular end-systolic diameter; NOAF, new-onset atrial fibrillation; PCl, percutaneous coronary intervention; RCA, right coronary artery; TnT, troponin T; WBC, white blood cell; ULN, upper limit of normal.

\section{Usefulness of GRACE RS in the prediction of post-MI NOAF}

GRACE RS, an important risk evaluation model originally designed for the prediction of 6-month mortality in patients with ACS, has also been demonstrated in various clinical settings with excellent discrimination performance. ${ }^{9}$ However, until now, few data were available with respect to the usefulness of GRACE RS in AF prediction. In the present study, GRACE RS was shown to be a useful tool for the prediction of post-MI NOAF (C-statistic: 0.76$)$ and was superior to the $\mathrm{CHA}_{2} \mathrm{DS}_{2}-\mathrm{VASc}$ score. To the best of our knowledge, this is the first study regarding the usefulness of GRACE RS in post-MI NOAF prediction.

The usefulness of GRACE RS for NOAF prediction in patients with STEMI is not surprising. First, several components included in GRACE RS have been demonstrated as the main risk factors for AF. For example, the Global Utilization of Streptokinase and TPA (alteplase) for Occluded Coronary 


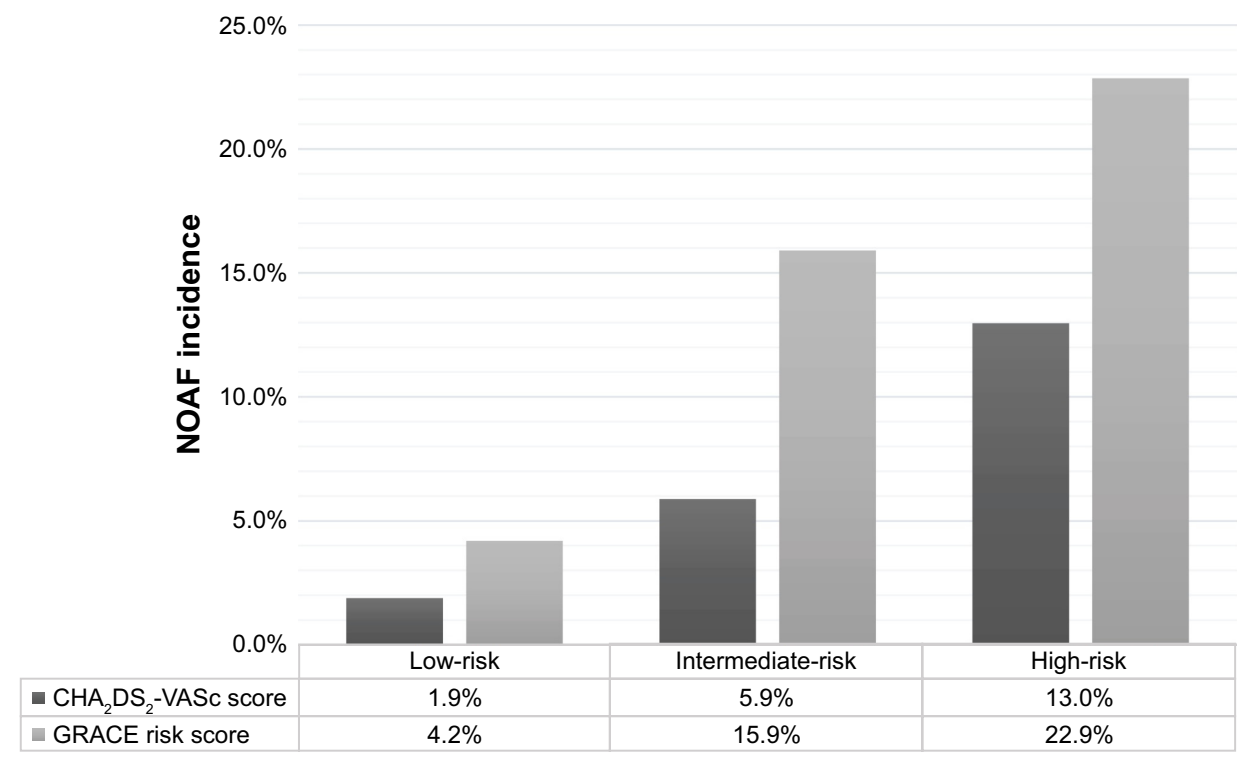

Figure 2 The incidence of NOAF based on GRACE and $\mathrm{CHA}_{2} \mathrm{DS}_{2}-\mathrm{VASc}$ scores stratification.

Notes: Low-risk: patients with GRACE risk score $\leq 125$ or $\mathrm{CHA}_{2} \mathrm{DS}_{2}$-VASc score $=0$ for male or I for female; Intermediate-risk: patients with GRACE risk score I26-I54 or $\mathrm{CHA}_{2} \mathrm{DS}_{2}$-VASc score=I for male or 2 for female; High-risk: patients with GRACE risk score $\geq 155$ or $\mathrm{CHA}_{2} \mathrm{DS}_{2}$-VASc score $\geq 2$ for male or $\geq 3$ for female.

Abbreviations: GRACE, Global Registry of Acute Coronary Events; NOAF, new-onset atrial fibrillation.

Arteries (GUSTO-I) investigators had validated that age, higher Killip class and heart rate, and lower SBP were independent predictors of NOAF complicating STEMI. ${ }^{3}$ Second, NOAF has often been perceived as a risk indicator reflecting the deterioration of heart failure, a major risk factor for death in patients with MI who generally had a higher GRACE RS compared with those not developing heart failure or NOAF. ${ }^{4}$ Indeed, we demonstrated a stepwise increased association between GRACE risk stratification and NOAF incidence (Figure 2).

In our subgroup analysis based on GRACE RS stratification, acceptable diagnostic performance was only observed in the low-risk group. However, this finding should not cast doubt on the usefulness of GRACE RS in intermediate- and high-risk groups because the limited numbers of patients and events might preclude the achievement of statistical significance (Table S3).

\section{Sex-related differences in GRACE and $\mathrm{CHA}_{2} \mathrm{DS}_{2}$-VASc scores for NOAF prediction}

The prognostic impact of sex-related differences in patients with ACS has been studied. ${ }^{19}$ In general, women with ACS tend to present with more atypical symptoms and have higher risk profiles and comorbidities. ${ }^{20}$ In line with previous studies, we also showed that women were at higher risk for developing post-MI NOAF in comparison with men. There- fore, it is necessary to explore the usefulness of GRACE and $\mathrm{CHA}_{2} \mathrm{DS}_{2}-\mathrm{VASc}$ scores across sex categories. Of note, in our study, GRACE RS only achieved a suboptimal calibration (HLS $p=0.05$ ) and discrimination (C-statistic: 0.69; 95\% CI: 0.59-0.78) in females, which was different from that in males (C-statistic: 0.74 ; 95\% CI: 0.70-0.78; HLS $p=0.37)$. However, this was not hard to imagine because female sex is not a component factor included in GRACE RS. As a result, caution is required when GRACE RS is used to evaluate the risk stratification of post-MI NOAF in females.

Several limitations of this study should be noted. First, this was a single-center retrospective study with a relatively small sample size; therefore, the results should be considered as hypothesis generating and warranting validation by multicenter studies. Second, although we had excluded patients with a history of AF based on medical records, there might be subjects who had asymptomatic AF events before the index STEMI being misclassified as NOAF, given the high prevalence of asymptomatic $\mathrm{AF} .{ }^{21}$ In fact, this is an inherent limitation almost to all studies regarding NOAF identification. ${ }^{7,17}$ Third, we sought to evaluate the usefulness of GRACE RS in the prediction of post-MI NOAF during hospitalization, its value in recurrent AF prediction was not assessed due to the lack of follow-up data. We also failed to demonstrate the detrimental impact of recurrent AF on clinical outcomes, which should be validated in the future. 
A

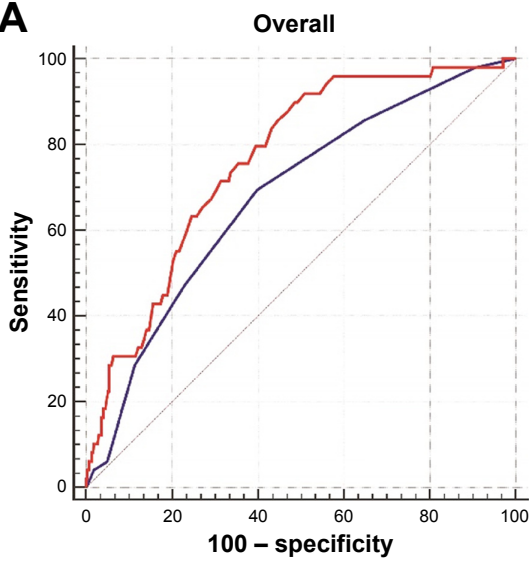

\begin{tabular}{|l|l|l|l|}
\hline Risk score & C-statistics $(95 \%$ Cl) & HLS, $p$-value & $p$-value \\
\hline CHA $_{2}$ DS $_{2}$-VASC & $0.68(0.64-0.72)$ & 0.90 & 0.03 \\
\hline GRACE RS & $0.76(0.72-0.80)$ & 0.40 & \\
\hline
\end{tabular}

D

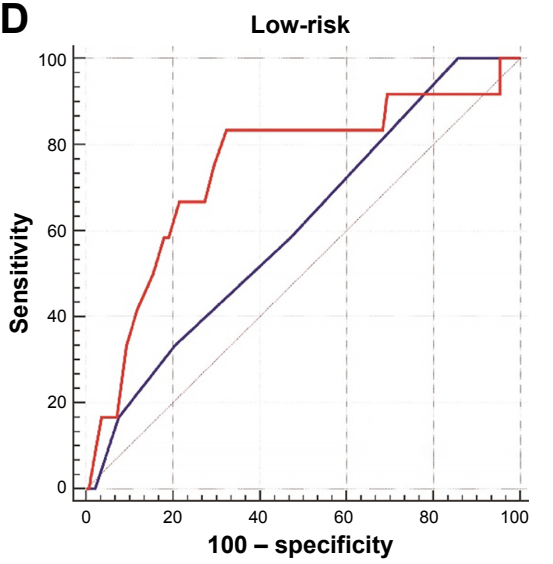

\begin{tabular}{|l|l|l|l|}
\hline Risk score & C-statistics $(95 \%$ Cl) & HLS, $p$-value & $p$-value \\
\hline CHA $_{2}$ DS $_{2}$-VASc & $0.61(0.55-0.66)$ & 0.67 & 0.22 \\
\hline GRACE RS & $0.75(0.69-0.79)$ & 0.24 & \\
\hline
\end{tabular}
B

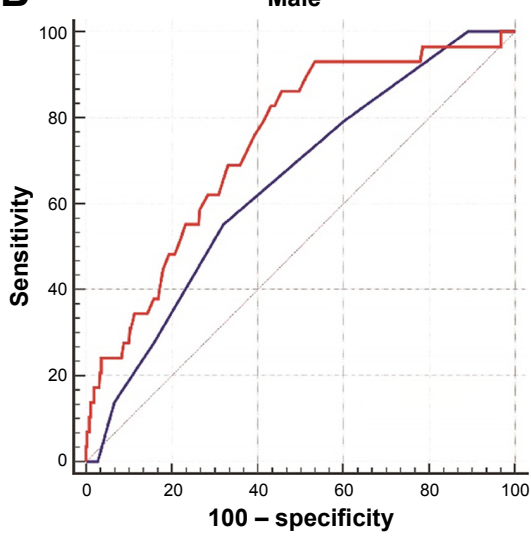

\begin{tabular}{|l|l|l|l|}
\hline Risk score & C-statistics $(95 \% \mathrm{Cl})$ & $\mathrm{HLS}, p$-value & $p$-value \\
\hline
\end{tabular} \begin{tabular}{|l|l|l|l|}
\hline $\mathrm{CHA}_{2} \mathrm{DS}_{2}$-VASc & $0.65(0.60-0.69)$ & 0.62 & 0.07 \\
\hline
\end{tabular}

\begin{tabular}{l|l|l|}
\hline GRACE RS & $0.74(0.70-0.78)$ & 0.37 \\
\hline
\end{tabular}

E

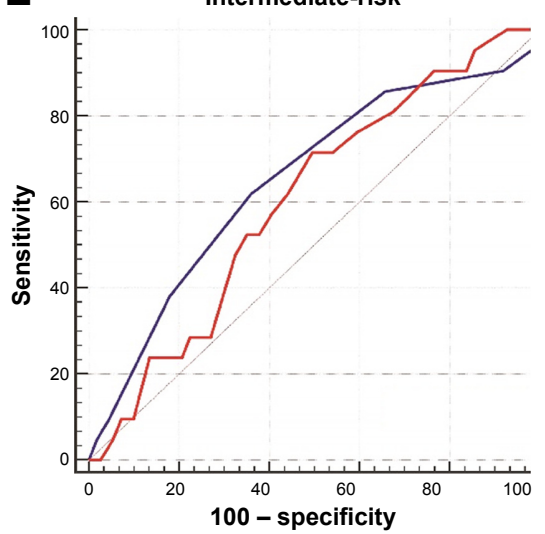

\begin{tabular}{|l|l|l|l|}
\hline Risk score & C-statistics $(95 \% \mathrm{Cl})$ & HLS, $p$-value & $p$-value \\
\hline CHA $_{2} \mathrm{DS}_{2}$-VASc & $0.65(0.56-0.73)$ & 0.56 & 0.58 \\
\hline GRACE RS & $0.60(0.51-0.69)$ & 0.81 & \\
\hline
\end{tabular}
C

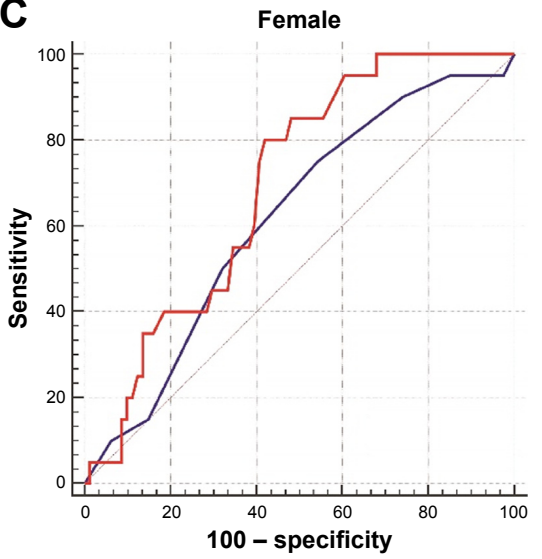

\begin{tabular}{|l|l|l|l|}
\hline Risk score & C-statistics $(95 \% \mathrm{Cl})$ & $\mathrm{HLS}, p$-value & $p$-value \\
\hline
\end{tabular} \begin{tabular}{|l|l|l|l|}
\hline CHA $_{2}$ DS $_{2}$-VASc & $0.62(0.51-0.71)$ & 0.79 & 0.34 \\
\hline GRACE RS & $0.69(0.59-0.78)$ & 0.05 & \\
\hline
\end{tabular}

F

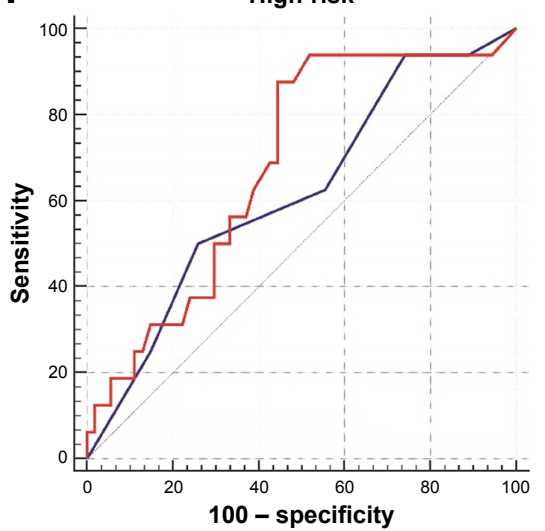

$$
\text { - } \mathrm{CHA}_{2} \mathrm{DS}_{2} \text {-VASC }- \text { GRACE RS }
$$

Figure 3 Comparison of the discrimination performance of GRACE RS and CHA DS, -VASc score in the prediction of post-MI NOAF.

Note: ap-value represents the comparison of $C$-statistics between GRACE RS and $\mathrm{CHA}_{2} \mathrm{DS}_{2}-\mathrm{VASc}$ score. (A) For the overall cohort, GRACE RS was significantly better than CHA $\mathrm{DS}{ }_{2}$ VASc score and both risk scores demonstrated excellent calibration; (B and $\mathbf{C}$ ) illustrated that GRACE RS appeared to be better than CHA DS 2 -VASc score for both men and women, respectively; (D to F) showed the comparisons between GRACE RS and CHA,DS 2 -VASc score based on risk stratification (low-, intermediate-, and high-risk groups, respectively). Abbreviations: GRACE, Global Registry of Acute Coronary Events; HLS, Hosmer-Lemeshow goodness-of-fit statistic; MI, myocardial infarction; NOAF, new-onset atrial fibrillation; RS, risk score.

Table 3 Independent risk factors for post-MI NOAF in the overall population

\begin{tabular}{|c|c|c|c|c|}
\hline Variables $^{a}$ & $\begin{array}{l}\text { Unadjusted } \\
\text { OR }(95 \% \mathrm{Cl})\end{array}$ & $p$-value & $\begin{array}{l}\text { Adjusted OR } \\
(95 \% \mathrm{Cl})\end{array}$ & $p$-value \\
\hline Age (+ 10 years) & $2.02(1.54-2.65)$ & $<0.01$ & $1.63(1.17-2.26)$ & $<0.01$ \\
\hline Female sex & $3.05(1.64-5.66)$ & $<0.01$ & $\mathrm{I} .30(0.62-2.7 \mathrm{I})$ & 0.48 \\
\hline Smoker & $0.29(0.15-0.57)$ & $<0.0$ I & $0.60(0.27-1.33)$ & 0.21 \\
\hline CKD & $2.25(I .2 I-4.2 I)$ & 0.01 & $1.05(0.51-2.16)$ & 0.90 \\
\hline $\mathrm{CHF}$ & $2.33(1.20-4.50)$ & 0.01 & I. $48(0.72-3.05)$ & 0.28 \\
\hline On-admission HF & $3.03(1.62-5.66)$ & $<0.01$ & $1.74(0.86-3.50)$ & 0.12 \\
\hline
\end{tabular}

Note: ${ }^{2}$ ariables with a $p$-value $<0.05$ in univariate analyses.

Abbreviations: $\mathrm{CHF}$, congestive heart failure; CKD, chronic kidney dysfunction; $\mathrm{HF}$, heart failure; NOAF, new-onset atrial fibrillation; MI, myocardial infarction; OR, odds ratio.

\section{Conclusion}

In patients with STEMI but no history of AF, the diagnostic performance of GRACE RS in the prediction of post-MI NOAF is better than that of the $\mathrm{CHA}_{2} \mathrm{DS}_{2}-\mathrm{VASc}$ score. With the use of GRACE RS, it will be convenient to identify patients with MI who are at high risk of subsequent NOAF and may benefit from enhanced electronic monitoring. Further prospective studies are warranted to validate our findings.

\section{Acknowledgments}

This work was supported by the National Natural Science Foundation of China (grant numbers 81270193 and 30800466). 


\section{Author contributions}

This manuscript was drafted by JC Luo. YD Wei and JC Luo contributed to the conception and design of the article. LM Dai, HQ Li, and ZQ Li contributed to the acquisition and analysis of data. JM Li, BX Liu, JL Zhao, and XM Qin contributed to the critical revision of the paper. All Authors contributed toward data analysis, drafting and revising the paper and agree to be accountable for all aspects of the work.

\section{Disclosure}

The authors report no conflicts of interest in this work.

\section{References}

1. Kundu A, O’Day K, Shaikh AY, et al. Relation of atrial fibrillation in acute myocardial infarction to in-hospital complications and early hospital readmission. Am J Cardiol. 2016;117(8):1213-1218.

2. Schmitt J, Duray G, Gersh BJ, Hohnloser SH. Atrial fibrillation in acute myocardial infarction: a systematic review of the incidence, clinical features, and prognostic implications. Eur Heart J. 2009;30(9): 1038-1045.

3. Crenshaw BS, Ward SR, Granger CB, Stebbins AL, Topol EJ, Califf RM. Atrial fibrillation in the setting of acute myocardial infarction: the GUSTO-I experience. Global Utilization of Streptokinase and TPA for Occluded Coronary Arteries. J Am Coll Cardiol. 1997;30(2): 406-413.

4. Jabre P, Roger VL, Murad MH, et al. Mortality associated with atrial fibrillation in patients with myocardial infarction: a systematic review and meta-analysis. Circulation. 2011;123(15):1587-1593.

5. Roffi M, Patrono C, Collet JP, et al. 2015 ESC Guidelines for the management of acute coronary syndromes in patients presenting without persistent ST-segment elevation: Task Force for the Management of Acute Coronary Syndromes in Patients Presenting without Persistent ST-Segment Elevation of the European Society of Cardiology (ESC). Eur Heart J. 2016;37(3):267-315.

6. Camm AJ, Kirchhof P, Lip GY, et al. Guidelines for the management of atrial fibrillation: the Task Force for the Management of Atrial Fibrillation of the European Society of Cardiology (ESC). Eur Heart J. 2010;31(19):2369-2429.

7. Saliba W, Gronich N, Barnett-Griness O, Rennert G. Usefulness of CHADS2 and CHA2DS2-VASc scores in the prediction of new-onset atrial fibrillation: a population-based study. Am J Med. 2016;129(8): 843-849.
8. Lau KK, Chan PH, Yiu KH, et al. Roles of the $\mathrm{CHADS}_{2}$ and $\mathrm{CHA}_{2} \mathrm{DS}_{2}-$ VASc scores in post-myocardial infarction patients: Risk of new occurrence of atrial fibrillation and ischemic stroke. Cardiol J. 2014;21(5): 474-483.

9. Eagle KA, Lim MJ, Dabbous OH, et al. A validated prediction model for all forms of acute coronary syndrome: estimating the risk of 6-month postdischarge death in an international registry. JAMA. 2004;291(22): 2727-2733.

10. McAllister DA, Halbesma N, Carruthers K, Denvir M, Fox KA. GRACE score predicts heart failure admission following acute coronary syndrome. Eur Heart J Acute Cardiovasc Care. 2015;4(2):165-171.

11. Park KL, Budaj A, Goldberg RJ, et al. Risk-prediction model for ischemic stroke in patients hospitalized with an acute coronary syndrome (from the Global Registry of Acute Coronary Events [GRACE]). Am J Cardiol. 2012;110(5):628-635.

12. Schnabel RB, Sullivan LM, Levy D, et al. Development of a risk score for atrial fibrillation (Framingham Heart Study): a community-based cohort study. Lancet. 2009;373(9665):739-745.

13. Benjamin EJ, Levy D, Vaziri SM, D’Agostino RB, Belanger AJ, Wolf PA. Independent risk factors for atrial fibrillation in a populationbased cohort. The Framingham Heart Study. JAMA. 1994;271(11): 840-844.

14. Thygesen K, Alpert JS, Jaffe AS, et al. Third universal definition of myocardial infarction. Circulation. 2012;126(16):2020-2035.

15. Fox KA, Fitzgerald G, Puymirat E, et al. Should patients with acute coronary disease be stratified for management according to their risk? Derivation, external validation, and outcomes using the updated GRACE risk score. BMJ Open. 2014;4(2):e004425.

16. Hanley JA, McNeil BJ. A method of comparing the areas under receiver operating characteristic curves derived from the same cases. Radiology. 1983;148(3):839-843

17. Batra G, Svennblad B, Held C, et al. All types of atrial fibrillation in the setting of myocardial infarction are associated with impaired outcome. Heart. 2016;102(12):926-933.

18. Mitchell LB, Southern DA, Galbraith D, Ghali WA, Knudtson M, Wilton SB. Prediction of stroke or TIA in patients without atrial fibrillation using CHADS2 and CHA2DS2-VASc scores. Heart. 2014; 100(19):1524-1530.

19. Mahajan K, Negi PC, Merwaha R, Mahajan N, Chauhan V, Asotra S. Gender differences in the management of acute coronary syndrome patients: One year results from HPIAR (HP-India ACS Registry). Int $J$ Cardiol. 2017;248:1-6.

20. Canto JG, Rogers WJ, Goldberg RJ, et al. Association of age and sex with myocardial infarction symptom presentation and in-hospital mortality. JAMA. 2012;307(8):813-822.

21. Sanna T, Diener HC, Passman RS, et al. Cryptogenic stroke and underlying atrial fibrillation. $N$ Engl J Med. 2014;370(26):2478-2486. 


\section{Supplementary materials}

Table SI Definitions of baseline comorbidities

\begin{tabular}{|c|c|}
\hline Baseline comorbidities & Definitions \\
\hline Hypertension, diabetes, dyslipidemia & Definitions of hypertension, ${ }^{1}$ diabetes, ${ }^{2}$ and dyslipidemia ${ }^{3}$ are conformed to current guidelines. \\
\hline Smoker & Smoker includes both previous and current smoker. \\
\hline Chronic kidney dysfunction (CKD) & $\begin{array}{l}\text { CKD is defined as a known history of CKD based on patients' medical records or an estimated glomerular } \\
\text { filtration rate }<60 \mathrm{~mL} / \mathrm{min} \text { calculated using CKD-EPI method. }{ }^{4}\end{array}$ \\
\hline Congestive heart failure (CHF) & $\begin{array}{l}\mathrm{CHF} \text { is considered in patients with a history of heart failure or a measured left ventricular ejection } \\
\text { fraction }<40 \% \text {. }\end{array}$ \\
\hline Vascular disease & $\begin{array}{l}\text { Vascular disease is defined as a medical history of myocardial infarction, percutaneous coronary intervention, } \\
\text { coronary artery bypass surgery, intermittent claudication, or the surgery of peripheral vessels. }\end{array}$ \\
\hline Cardiac arrest & $\begin{array}{l}\text { Cardiac arrest is defined as hemodynamic collapse from ventricular arrhythmias and impaired cardiac } \\
\text { pumping function, where patients needed to be revived urgently with vasoactive medications or electrical } \\
\text { defibrillation. }\end{array}$ \\
\hline Impaired mitral function & $\begin{array}{l}\text { The impaired mitral function is considered if mitral regurgitation is evaluated as moderate or serious based } \\
\text { on current guideline. }{ }^{5}\end{array}$ \\
\hline
\end{tabular}

Abbreviations: CKD, chronic kidney dysfunction; $\mathrm{CHF}$, congestive heart failure.

Table S2 Baseline characteristics of included patients based on sex category

\begin{tabular}{|c|c|c|c|c|c|c|}
\hline \multirow[t]{2}{*}{ Variables } & \multicolumn{3}{|l|}{ Male } & \multicolumn{3}{|l|}{ Female } \\
\hline & $\begin{array}{l}\text { SR } \\
(n=358)\end{array}$ & $\begin{array}{l}\text { NOAF } \\
(n=29)\end{array}$ & $p$-value & $\begin{array}{l}S R \\
(n=8 I)\end{array}$ & $\begin{array}{l}\text { NOAF } \\
(n=20)\end{array}$ & $p$-value \\
\hline Age (years) & $62.1 \pm 11.5$ & $69.6 \pm 10.2$ & $<0.01$ & $72.4 \pm 11.9$ & $80.5 \pm 8.2$ & $<0.01$ \\
\hline Hypertension (\%) & $232(64.8)$ & $18(62.1)$ & 0.77 & $48(59.3)$ & $15(75.0)$ & 0.19 \\
\hline Diabetes (\%) & $119(33.2)$ & $9(3 \mid .0)$ & 0.81 & $30(37.0)$ & $8(40.0)$ & 0.81 \\
\hline Dyslipidemia (\%) & $216(60.3)$ & $19(65.5)$ & 0.58 & $37(45.7)$ & $14(70.0)$ & 0.06 \\
\hline Smoker (\%) & $226(63.1)$ & $12(4 \mid .4)$ & 0.02 & $7(8.6)$ & 0 & 0.89 \\
\hline CKD (\%) & $63(17.6)$ & I3 (44.8) & $<0.01$ & $27(33.3)$ & $5(25.0)$ & 0.47 \\
\hline $\mathrm{CHF}(\%)$ & 49 (13.7) & $13(44.8)$ & $<0.01$ & $21(25.9)$ & $2(10.0)$ & 0.22 \\
\hline Previous stroke/TIA (\%) & $33(9.2)$ & $2(6.9)$ & 0.93 & $12(14.8)$ & $3(15.0)$ & 1.00 \\
\hline Previous vascular disease (\%) & $30(8.4)$ & $3(10.3)$ & 0.99 & $9(I I . I)$ & $2(10.0)$ & 1.00 \\
\hline Previous MI (\%) & $17(4.7)$ & I (3.4) & 1.00 & $4(4.9)$ & I (5.0) & 1.00 \\
\hline Previous PCl (\%) & $23(6.4)$ & $3(10.3)$ & 0.67 & $8(9.9)$ & $2(10.0)$ & 1.00 \\
\hline On-admission Killip class (\%) & & & 0.01 & & & 0.04 \\
\hline 1 & $303(84.6)$ & $21(72.4)$ & & $60(74.1)$ & $9(45.0)$ & \\
\hline II & $4 I(I I .5)$ & $2(6.9)$ & & $15(18.5)$ & $9(45.0)$ & \\
\hline III-IV & $14(3.9)$ & $6(20.7)$ & & $6(7.4)$ & $2(10.0)$ & \\
\hline On-admission HF (\%) ${ }^{\mathrm{a}}$ & $55(15.4)$ & $8(27.6)$ & 0.15 & $21(25.9)$ & II (55.0) & 0.01 \\
\hline On-admission SBP (mmHg) & $133.3 \pm 22.0$ & $120.4 \pm 26.0$ & $<0.01$ & $131.3 \pm 24.7$ & $137.9 \pm 22.0$ & 0.28 \\
\hline On-admission HR (bpm) & $80.1 \pm 17.1$ & $83.7 \pm 20.6$ & 0.28 & $81.9 \pm 15.8$ & $83.4 \pm 21.3$ & 0.74 \\
\hline Cardiac arrest (\%) & $8(2.2)$ & I (3.4) & 1.00 & $\mathrm{I}(\mathrm{I} .2)$ & I (5.0) & 0.36 \\
\hline $\mathrm{CHA}_{2} \mathrm{DS}_{2}$-VASc score & $2.1 \pm 1.5$ & $2.8 \pm 1.3$ & 0.01 & $3.7 \pm 1.8$ & $4.4 \pm 1.5$ & 0.13 \\
\hline GRACE risk score & $1 \mid 6.4 \pm 27.1$ & $|44.0 \pm 38|$. & $<0.01$ & $137.7 \pm 32.9$ & $\mid 57.1 \pm 25.1$ & 0.02 \\
\hline In-hospital death (\%) & $13(3.6)$ & $4(13.8)$ & 0.04 & $6(7.4)$ & $3(15.0)$ & 0.53 \\
\hline Hospitalization (days) & $7.0 \pm 3.3$ & $10.3 \pm 4.6$ & $<0.01$ & $8.6 \pm 6.2$ & 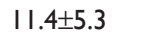 & 0.07 \\
\hline
\end{tabular}

Notes: ${ }^{a}$ On-admission Killip class $>$ I. Data presented as $\mathrm{n}(\%)$ or mean \pm SD.

Abbreviations: CHF, chronic heart failure; CKD, chronic kidney dysfunction; GRACE, Global Registry of Acute Coronary Events; HF, heart failure; HR, heart rate; MI, myocardial infarction; NOAF, new-onset atrial fibrillation; PCl, percutaneous coronary intervention; SBP, systolic blood pressure; SR, sinus rhythm; TIA, transient ischemic attack. 
Table S3 Baseline characteristics of included patients based on GRACE risk score stratification

\begin{tabular}{|c|c|c|c|c|c|c|c|c|c|}
\hline \multirow[t]{2}{*}{ Variables } & \multicolumn{3}{|c|}{$\begin{array}{l}\text { Low-risk (GRACE risk } \\
\text { score } \leq 125 \text { ) }\end{array}$} & \multicolumn{3}{|c|}{$\begin{array}{l}\text { Intermediate-risk (GRACE risk } \\
\text { score | } 26-154 \text { ) }\end{array}$} & \multicolumn{3}{|c|}{$\begin{array}{l}\text { High-risk (GRACE risk } \\
\text { score } \geq 155 \text { ) }\end{array}$} \\
\hline & $\begin{array}{l}\text { SR } \\
(n=274)\end{array}$ & $\begin{array}{l}\text { NOAF } \\
(n=12)\end{array}$ & $p$-value & $\begin{array}{l}\text { SR } \\
(n=I I I)\end{array}$ & $\begin{array}{l}\text { NOAF } \\
(n=2 I)\end{array}$ & $p$-value & $\begin{array}{l}\text { SR } \\
(n=54)\end{array}$ & $\begin{array}{l}\text { NOAF } \\
(n=16)\end{array}$ & $p$-value \\
\hline Age (years) & $57.2 \pm 8.3$ & $61.3 \pm 7.5$ & 0.09 & $72.9 \pm 8.1$ & $75.7 \pm 6.5$ & 0.13 & $80.4 \pm 8.4$ & $81.4 \pm 9.2$ & 0.68 \\
\hline Female (\%) & $26(9.5)$ & I (8.3) & 1.00 & $33(29.7)$ & II (52.4) & 0.04 & $22(40.7)$ & $8(50.0)$ & 0.51 \\
\hline Hypertension (\%) & I 64 (59.9) & $9(75.0)$ & 0.45 & $72(64.9)$ & $16(76.2)$ & 0.31 & 44 (8I.5) & $8(50.0)$ & 0.03 \\
\hline Diabetes (\%) & $84(30.7)$ & $4(33.3)$ & 1.00 & $42(37.8)$ & $7(33.3)$ & 0.70 & $23(42.6)$ & $6(37.5)$ & 0.72 \\
\hline Dyslipidemia (\%) & I74 (63.5) & $9(75.0)$ & 0.61 & $54(48.6)$ & 13 (6I.9) & 0.27 & $25(48.1)$ & II (68.8) & 0.15 \\
\hline Smoker (\%) & $179(65.3)$ & $5(4 \mid .7)$ & 0.17 & $41(36.9)$ & $4(19.0)$ & 0.11 & $13(24.1)$ & $3(18.8)$ & 0.92 \\
\hline CKD (\%) & $23(8.4)$ & $4(33.3)$ & 0.02 & $32(28.8)$ & $6(28.6)$ & 0.98 & $27(50.0)$ & $6(37.5)$ & 0.38 \\
\hline CHF (\%) & $26(9.5)$ & $4(33.3)$ & 0.03 & $22(19.8)$ & $6(28.6)$ & 0.54 & $22(40.7)$ & $5(3 \mid .2)$ & 0.49 \\
\hline Previous stroke/TIA (\%) & $18(6.6)$ & 0 & 0.76 & $12(10.8)$ & $4(19.0)$ & 0.49 & $15(27.8)$ & $\mathrm{I}(6.2)$ & 0.14 \\
\hline Previous vascular disease (\%) & $20(7.3)$ & I (8.3) & 1.00 & $15(13.5)$ & I (4.8) & 0.45 & $3(5.6)$ & $3(18.8)$ & 0.25 \\
\hline Previous MI (\%) & $12(4.4)$ & 0 & 1.00 & $7(6.3)$ & 0 & 1.00 & $2(3.7)$ & $2(12.5)$ & 0.22 \\
\hline Previous PCI (\%) & $17(6.2)$ & $\mathrm{I}(8.3)$ & 1.00 & $10(9.0)$ & $\mathrm{I}(4.8)$ & 0.83 & $4(7.4)$ & $3(18.8)$ & 0.39 \\
\hline On-admission Killip class (\%) & & & 0.70 & & & 0.65 & & & 0.92 \\
\hline 1 & $254(92.7)$ & $12(100)$ & & $88(79.3)$ & $17(81.0)$ & & $21(38.9)$ & $\mathrm{I}(6.3)$ & \\
\hline II & $20(7.3)$ & 0 & & $19(17.1)$ & $4(19.0)$ & & $17(3 \mid .5)$ & $7(43.8)$ & \\
\hline III-IV & - & - & & $4(3.6)$ & 0 & & $16(29.6)$ & $8(50.0)$ & \\
\hline On-admission $\mathrm{HF}^{\mathrm{a}}$ & $20(7.3)$ & 0 & 0.70 & $23(20.7)$ & $4(19.0)$ & 1.00 & $33(6 I . I)$ & $15(93.8)$ & 0.01 \\
\hline On-admission SBP $(\mathrm{mmHg})$ & $135.8 \pm 21.8$ & $|3| .5 \pm 27 . \mid$ & 0.51 & $|3| .3 \pm 20.3$ & $135.0 \pm 22.9$ & 0.46 & $|2| .4 \pm 26 . \mid$ & II $4.8 \pm 24.7$ & 0.37 \\
\hline On-admission HR (bpm) & $79.9 \pm 15.9$ & $90.0 \pm 17.2$ & 0.03 & $79.7 \pm 17.5$ & $74.6 \pm 17.5$ & 0.22 & $84.8 \pm 19.9$ & $90.6 \pm 23.2$ & 0.33 \\
\hline Cardiac arrest (\%) & I $(0.4)$ & 0 & 1.00 & $2(1.8)$ & I (4.8) & 0.41 & $6(11.1)$ & I (6.2) & 0.92 \\
\hline $\mathrm{CHA}_{2} \mathrm{DS}_{2}$-VASc score & $1.6 \pm 1.2$ & $2.1 \pm 1.2$ & 0.20 & $3.2 \pm 1.4$ & $3.9 \pm 1.5$ & 0.03 & $4.5 \pm 1.7$ & $3.8 \pm 1.5$ & 0.13 \\
\hline GRACE risk score & $102.4 \pm 15.9$ & $113.6 \pm 15.4$ & 0.02 & $137.8 \pm 7.8$ & $|40.3 \pm 7|$. & 0.18 & $175.1 \pm 19.4$ & $\mid 88.1 \pm 25.8$ & 0.03 \\
\hline In-hospital death (\%) & $5(1.8)$ & I (8.3) & 0.61 & $2(1.8)$ & $2(9.5)$ & 0.12 & $12(22.2)$ & $4(25.0)$ & 1.00 \\
\hline Hospitalization (days) & $6.8 \pm 3.0$ & $8.8 \pm 3.1$ & 0.03 & $8.4 \pm 5.3$ & $9.7 \pm 5.1$ & 0.30 & $7.9 \pm 5.1$ & $13.6 \pm 4.5$ & $<0.01$ \\
\hline
\end{tabular}

Notes: ${ }^{\mathrm{O} O n-a d m i s s i o n ~ K i l l i p ~ c l a s s ~}>$ I. Data presented as $\mathrm{n}(\%)$ or mean $\pm \mathrm{SD}$.

Abbreviations: CHF, chronic heart failure; CKD, chronic kidney dysfunction; GRACE, Global Registry of Acute Coronary Events; HF, heart failure; HR, heart rate; MI, myocardial infarction; NOAF, new-onset atrial fibrillation; PCl, percutaneous coronary intervention; SBP, systolic blood pressure; SR, sinus rhythm; TIA, transient ischemic attack. 
Table S4 Optimal cut-off value and corresponding sensitivity and specificity of GRACE and $\mathrm{CHA}_{2} \mathrm{DS}_{2}$-VASc scores

\begin{tabular}{|c|c|}
\hline Predictive model (optimal cut-off value) & Diagnostic accuracy \\
\hline \multicolumn{2}{|l|}{ Overall cohort } \\
\hline \multirow[t]{2}{*}{ GRACE risk score $(>118)$} & Specificity: $51.3 \%$ \\
\hline & Sensitivity: $89.8 \%$ \\
\hline \multirow[t]{2}{*}{$\mathrm{CHA}_{2} \mathrm{DS}_{2}-\mathrm{VASc}$ score $(>2)$} & Specificity: $60.4 \%$ \\
\hline & Sensitivity: $69.4 \%$ \\
\hline \multicolumn{2}{|l|}{ Sex category } \\
\hline \multicolumn{2}{|l|}{ Male } \\
\hline \multirow[t]{2}{*}{ GRACE risk score $(>116)$} & Specificity: $54.2 \%$ \\
\hline & Sensitivity: $86.2 \%$ \\
\hline \multirow[t]{2}{*}{$\mathrm{CHA}_{2} \mathrm{DS}_{2}-\mathrm{VASc}$ score $(>2)$} & Specificity: $68.2 \%$ \\
\hline & Sensitivity: $55.2 \%$ \\
\hline \multicolumn{2}{|l|}{ Female } \\
\hline \multirow[t]{2}{*}{ GRACE risk score $(>\mid 40)$} & Specificity: $58.0 \%$ \\
\hline & Sensitivity: $80.0 \%$ \\
\hline \multirow[t]{2}{*}{$\mathrm{CHA}_{2} \mathrm{DS}_{2}$-VASc score $(>3)$} & Specificity: $45.7 \%$ \\
\hline & Sensitivity: $75.0 \%$ \\
\hline \multicolumn{2}{|l|}{ GRACE risk score stratification } \\
\hline \multicolumn{2}{|l|}{ Low-risk $(\leq 125)$} \\
\hline \multirow[t]{2}{*}{ GRACE risk score $(>|I| 2)$} & Specificity: $67.9 \%$ \\
\hline & Sensitivity: $83.3 \%$ \\
\hline \multirow[t]{2}{*}{$\mathrm{CHA}_{2} \mathrm{DS}_{2}$-VASc score $(>0)$} & Specificity: $13.9 \%$ \\
\hline & Sensitivity: $100 \%$ \\
\hline \multicolumn{2}{|l|}{ Intermediate-risk (I26 to I54) } \\
\hline \multirow[t]{2}{*}{ GRACE risk score $(>136)$} & Specificity: $50.5 \%$ \\
\hline & Sensitivity: $71.4 \%$ \\
\hline \multirow[t]{2}{*}{$\mathrm{CHA}_{2} \mathrm{DS}_{2}-\mathrm{VASc}$ score $(>3)$} & Specificity: $64.0 \%$ \\
\hline & Sensitivity: $61.9 \%$ \\
\hline \multicolumn{2}{|l|}{ High-risk ( $\geq 155$ ) } \\
\hline \multirow[t]{2}{*}{ GRACE risk score $(>170)$} & Specificity: $55.6 \%$ \\
\hline & Sensitivity: $87.5 \%$ \\
\hline \multirow[t]{2}{*}{$\mathrm{CHA}_{2} \mathrm{DS}_{2}$-VASc score $(\leq 3)$} & Specificity: $74.1 \%$ \\
\hline & Sensitivity: $50.0 \%$ \\
\hline
\end{tabular}

Abbreviation: GRACE, Global Registry of Acute Coronary Events.

\section{References}

1. Daskalopoulou S, Khan N, Quinn R, et al. The 2012 Canadian hypertension education program recommendations for the management of hypertension: blood pressure measurement, diagnosis, assessment of risk, and therapy. Can J Cardiol. 2012;28(3):270-287.

2. American Diabetes Association. Diagnosis and classification of diabetes mellitus. Diabetes Care. 2011;34(Suppl 1):S62-S69.

3. Anderson T, Grégoire J, Hegele R, et al. 2012 update of the Canadian Cardiovascular Society guidelines for the diagnosis and treatment of dyslipidemia for the prevention of cardiovascular disease in the adult. Can J Cardiol. 2013;29(2):151-167.
4. Levey A, Stevens L, Schmid C, et al. A new equation to estimate glomerular filtration rate. Ann Intern Med. 2009;150(9):604-612.

5. Lang R, Badano L, Mor-Avi V, et al. Recommendations for cardiac chamber quantification by echocardiography in adults: an update from the American Society of Echocardiography and the European Association of Cardiovascular Imaging. $J$ Am Soc Echocardiogr. 2015;28(1): $1-39 . e 14$.
Clinical Interventions in Aging

\section{Publish your work in this journal}

Clinical Interventions in Aging is an international, peer-reviewed journal focusing on evidence-based reports on the value or lack thereof of treatments intended to prevent or delay the onset of maladaptive correlates of aging in human beings. This journal is indexed on PubMed Central, MedLine,
CAS, Scopus and the Elsevier Bibliographic databases. The manuscript management system is completely online and includes a very quick and fair peer-review system, which is all easy to use. Visit http://www.dovepress. $\mathrm{com} /$ testimonials.php to read real quotes from published authors. 